Apart from the rarity of laryngeal diphtheria in advanced life the case is of interest in the following respects. The pernicious doctrine which has received support in two of the most recent textbooks on diseases of the throat-that antitoxin is of no value after the fifth day of disease-is falsified by the rapid subsidence of the symptoms after injection of the large doses which the patient received. The absence of any serum reaction was due partly to the use of a refined serum and partly to the fact, which I have illustrated on several previous occasions, that serum reactions are often absent or ill marked after. severe angina in spite of the administration of large amounts of serum.

Recovery was all the more remarkable as the prognosis of laryngeal diphtheria in adult life is usually unfavourable.

Lastly the case is an excellent example of what C. Zoeller, ${ }^{3}$ who has recently recorded an attack of laryngeal diphtheria in a middle-aged man, describes as the "caprices of spontaneous immunization."

The great majority of town dwellers-especially those in capitals such as London and Paris, where diphtheria is endemic-undergo a process of occult spontaneous immunization, and only a comparatively small minority contract the disease. In some cases, however, this process of spontaneous immunization does not take place. Zoeller's patient was a colonel aged 50, who, in spite of the fact that he had been living in Paris and other communities where diphtheria was prevalent, had not become spontaneously immunized, but had contracted an attack of isolated laryngeal diphtheria followed by extensive paralysis, the laryngeal involvement being attributed to the fact that he was a heavy smoker.

In my patient tobacco could be excluded, and the involvement of the larynx was merely due to the natural course of the disease.

REFERENCES,

1 C'lin. Journ., 1916; xlv, 389. "British Medical Jomrnal, 1925, i, 733. - Bull. et Mém. Soc. Méd. Hôp. de Paris, 1928. lii, 426.

\section{TREATMENT OF FRACTURES OF THE CLAVICLE.} BY

H. H. GREENWOOD, M.B., B.S.LoND., F.R.C.S., SURGEON TO THE G.W.R. HOSPITAL, SWINDON.

Is the British Medical Journal of April 28th (p. 723) there was a comment on the treatment of fractures of the nlavicle, with a reference to modifications of the usual Sayre's adhesive plaster method. Whatever rariant be employed, adhesive plaster condemns a strong hairy man to a month or so of mild purgatory, and inflicts on the more tender skin of a woman or a child an irritation that is wellnigh intolerable; over the scene of the final removal of the plaster it is better to draw a veil.

In the majority of cases of fractured clavicle the fracture is situated somewhere within the inner two-thirds. Leaving out those rare and troublesome fractures close up to the sterno-clavicular joint, and those near to the acromioclavicular joint, which present special problems in treatment, these fractures can be adequately treated by the padded ring method. This is no new idea, but the rings which I have used for the past two years in hospital and private cases are, I believe, an advance on previous devices. The rings are made of wash-leather tightly packed with wool, and having incorporated with the wool a spring. They have been made for me by Mr. Walgrove, of 4, Hurdwick Place, Harrington Square, N.W.1.

The method of application is important. The anterior strap of webbing is drawn sufficiently tight to keep the anterior part of the ring in the sulcus internal to the head of the humerus, so that on pulling back the rings pressure backwards is made on the outer fragment. The strap is fastened to the ring on each side by a stout safety-pin, and should then lie across the chest above the level of the mammae. Two straps are used behind, and are drawn up as tightly as comfort will allow; they. also are pinned to the rings. Generally it will be found that on the next and succeeding davs the patient will tolerate further shortening of the posterior straps. When the rings are efficiently adjusted the arm of the affected side is placed across the front of the chest with the hand pointing towards the opposite shoulder, and loosely fixed there by any convenient method-bandage or sling. The thickness of the ring arts as an axillary pad, giving leverage outwards of the outer fragment.
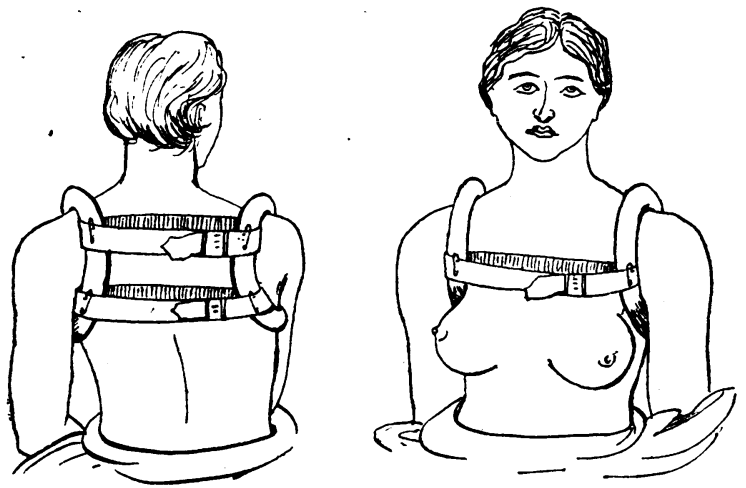

I have found this method far more effective than any plaster method for the majority of cases, and as to comfort there is no comparison. In a busy out-patient department the saving of time is considerable. It is so simple that nurses quickly learn how to adjust the rings, and the patient only needs inspection by the surgeon before being allowed to go home. One young amateur jockey with a comminuted fracture found himself so comfortable that at the end of a fortnight he could ride at full gallop without discomfort - needless to say, without the surgeon's permission.

From the illustrations it will be seen that the appliance leaves free the breast in the female, neither pressing on nor irritating that organ. Usually it will be found that the most effective leverage is secured by tightening the up,per strap behind, while the lower strap is only drawn sufficiently tight to counterbalance the pull of the anterior strap.

In the earlier rings made for me I tried a covering of rubber sheeting, but this soon perished; it was more expensive, it gave less secure purchase for the safety-pins, and caused unpleasant sweating in the axillae.

\section{PYREXIA DUE TO INFECTED DEAD TEETH.}

BY

LEONARD G. J. MACKEY, M.D., M.R.C.P., HONORARY PHYSICIAN TO THE QUEEN'S HOSPITAL, BIRMIYGHAM, AND TO THE BIRMINGHAM AND MIDLAND HOSPTTAL FOR WOMEN.

THE following three cases are interesting examples of a prolonged fever arising from apical abscesses, and they have several features in common-namely :

1. The fever was considerable and of long duration in each case, and terminated at once on extraction of the infected tooth or teeth.

2 . In none of the cases is it known when the fever began; so it may have been of much longer duration than is shown by the charts.

3. All three patients complained only of vague ill health; they had no pain and there were no symptoms pointing to any known disease. In Case I I had the patient's temperature taken most carefully to make sure that she was not malingering. In Case II the patient protested that he felt well enough to be in his shop and resented being kept in bed. In.Case III the patient refused to remain in bed after two weeks and returned to his business.

4. In all three cases the discovery of the lesion was made by a radiologist. In Case $I$ a solitary abscessed tooth was scen by the radiologist in skiagrams taken of the nasal sinuises. In Case II the abscessed stump was completely covered by clean healthy gum. In Case III the abscessed teeth were discovered amongst sereral root-filled teeth by the radiologist. 
It is not improbable that some of the apparently healthy possessors of abscessed teeth would prove to be running an evening temperature if they submitted themselves to the test of the thermometer. It

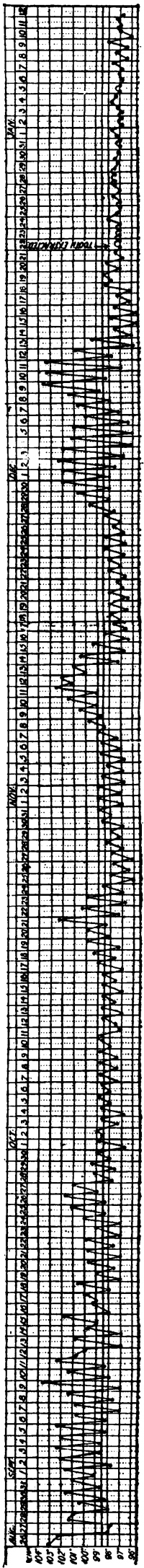
is also probable that a pyrexia which is attributed to the patient's illness is sometimes due to an unsuspected root infection, and that if encountered, say, after an operation, or after an attack of pneumonia, or in a person with valvular disease, it might be the cause of much anxiety to both patient and doctor.

It cannot be too frequently stated that root abscesses are quite common in the apparently edentulous, and the fact that a patient has clean empty gums does not warrant us neglecting to advise an $x$-ray examination of them if the patient's clinical symptoms are such as can be caused by some obscure focus of infection.

Vague ill health, brachial neuritis and sciatica, fibrositis, weakness of the heart muscle, andmay I add?-pyrexia are among the least serious consequences of root abscess.

\section{CaSe I.-Pyrexia for Seventeen} Weeks.

The patient was a middle-aged lady whom I saw in consultation with Dr. L. Kirkby Thomas in 1921.

Sho had had a febrile illness for seventeen weeks, without any physical signs or symptoms that afforded the slightest clue to the cause of her.high temperature, which at times reached 1030 , as is shown in the accompanying chart. All the investigations usually carried out in such a caso proved fruitless, including, I am ashamed to say, tests carried out at my suggestion to discover if she was malingering.

Finally, we decided to have her sinuses radiographed, and, though they proved normal, the radiograph revealed an abscess at the root of a solitary tooth.

With the extraction of the tooth on the following day the pyrexia ceased, and her health, which had been somewhat affected by her long fever, rapidly improved, and has remained good up to the present day.

The temperature chart was made by the nurses in attendance on the patient. No one knows when the pyrexia began.

Case II.-Pyreria for Six Weeks.

This patient, a middle-aged man, was under the care of Dr. G. C. Hartley, who was first called to see him in January last because the patient's wife discovered that her husband had a high temperature every evening. Dr. Hartley, finding no obvious cause for the pyrexia except a suspicious tooth, had the tooth extracted; in spite of this, however, the pyrexia continued.

Eventually the patient was admitted into the Queen's Hospital, and I investigated his condition in the usual way; but all tests, including blood cultures and Widal and Wassermann reactions, proved negative. A radiograph of the patient's gums, however, revealed a small abscessed

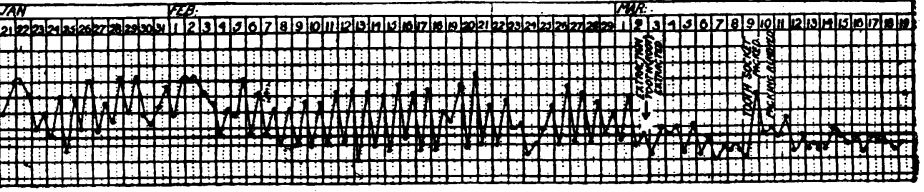

CASE II.

root of which there was no part visible from the mouth. This root was extracted, and for the first time since the discovery of the pyrexia the temperature became normal. A few days later, on account of bleeding; the socket was plugged, and the temperature immediately rose again. The next day the plug was removed, and the temperature fell to normal and has remained so ever since.

The accompanying temperature chart was commenced by Dr. Hartley when the patient was in his charge, and was continued by the nurses at the Queen's Hospital. It is not known when the pyrexia began. 